\title{
The Impact of I-Performance in Changing the Work Culture of Lecturers to Increase the Productivity of Three Pillars (Tri Dharma) of Higher Education in Indonesia
}

\author{
Muhammad Rozahi Istambul \\ Department of Information System, Faculty of Engineering, Widyatama University, Indonesia
}

Copyright@2019 by authors, all rights reserved. Authors agree that this article remains permanently open access under the terms of the Creative Commons Attribution License 4.0 International License

\begin{abstract}
Lecturers at universities in Indonesia have a work culture based on performance on Tri Dharma, namely teaching; research; and community service. Teaching is a performance that is often done by lecturers because it has become a pattern of routines every semester. However, the lecturer research performance in a ratio between the number of lecturers and the number of publications is still not optimal. This is based on the observation of the Indonesian Minister of Research and Technology (Menristekdikti) in July 2018, that recently Indonesia only recorded 13,250 titles of published journals from the previous record of 5,499 titles in 2015. Likewise, the performance of community services is still not optimal just like the assessment of research performance. The application of the I-Performance is one of the strategies to increase the productivity of lecturer performance in a university in Indonesia and will help change the work culture in increasing the amount of research and community service. The application of I-Performance will be the controller for the lecturers in taking responsibility for their work program. In addition to being able to plan and implement its own work program, this application can also see the progress of the activities in real time which can automatically be monitored by both the lecturer and the leader.
\end{abstract}

Keywords I-Performance, Work Culture, Increase Productivity, Tri Dharma

\section{Introduction}

In general, the work culture of higher education in Indonesia still encourages its lecturers to carry out performance in the Tri Dharma of Higher Education, which is a mandate from the Indonesian government. However, currently, most lecturers are still focusing on teaching performance. This is because there are still many universities that have not been able to facilitate the needs of lecturers who will conduct research and service. The teaching field gets high performance because it is routinely implemented and there are monitoring and evaluation to control the performance.

It is different from the performance in the field of research and community service, which is only carried out by motivated lecturers. As a result, lecturers in their performance only focus on teaching, although a number of universities have also facilitated research activities and community services to implement rewards for lecturers who fulfill and punishment for lecturers who do not fulfill them. Reward and punishment have also not been able to increase the productivity of lecturers performance because all of these activities are only monitored and controlled based on findings or lecturers get the convenience of not carrying it out because of other activities.

In resolving these performance problems, universities need a strategy with the help of information technology, which is applying the application of I-Performance (Information Performance) to each lecturer. I-Performance will help every lecturer to improve performance productivity because each performance activity will be planned by the lecturer and recorded at any time in the database. I-Performance will display the information of each lecturer in real time according to the progress reported by the lecturer in question, this is a motivation for the lecturer considering that each activity carried out will receive a score that will be recapitulated.

The use of I-Performance becomes the controller and motivation for each lecturer given the success of experience in universities that use e-learning for students. The results based on the research show that there is an 
increase in students' knowledge and abilities in conducting the learning process. (M. Rozahi, 2016).

The increase in productivity by itself will increase because lecturers who carry out research and community service performance will feel motivated since they would also get a valuation as well as teaching performance. Of course, lecturers will routinely look for and make a program that leads to research and community services that will later give an impact on their I-Performance. The recording of data into I-Performance is carried out by the lecturer concerned who performs the activity so that the monitoring process can also be seen by related parties, namely the lecturer concerned and the leader.

I-Performance will condition the milestones from each initial planning to the final report inputted by the lecturer in question and the application will provide alerts on deadline times that become the performance targets that must be immediately resolved. Control of the I-Performance application will evaluate in three ways, namely: real-time conditions for lecturers who have completed performance according to planning; performance completed but past the completion schedule; until the unresolved performance. I-Performance real-time assessment would become the final assessment for the lecturer performance score in question.

The purpose of this article is to be a pilot to be used in a number of other universities in Indonesia since the lecturer will compete to determine the productivity of their performance in accordance with their ability to be planned later by themselves until the completion.

\section{Research Approach and Methodology}

The need for changes in increasing the lecturer productivity performance in carrying out Tri Dharma of Higher Education in Indonesia is very important by making a number of achievement strategies. In this study, the strategy in question is to implement I-Performance, which is an embedded application that is applied to a performance system in college. The methodology stages carried out to implement I-Performance to control the performance of the lecturer consist of the following steps:

1. Rules, in this case, it is the first step to provide guidance on the assessment of lecturers' performance that refers to the proposed program that is self-created by the lecturer concerned,

2. Planning, the proposed program that the lecturer makes will set a number of parameters from implementation time until reporting schedule,

3. Software, the application provided will manage each input parameter from the lecturer to be reminded and recapitulated for the interested parties,

4. Behavior, implementation of the responsibilities of lecturers in carrying out activities according to their respective abilities,
5. Supervision, the application will remind as a basis for monitoring the transparency of the activities being carried out by the lecturer,

6. Evaluation, the recapitulation of the results of all activities can be monitored by the leaders and lecturers concerned in real time.

As in the following picture, that each stage will influence each other for the occurrence of a change in performance.

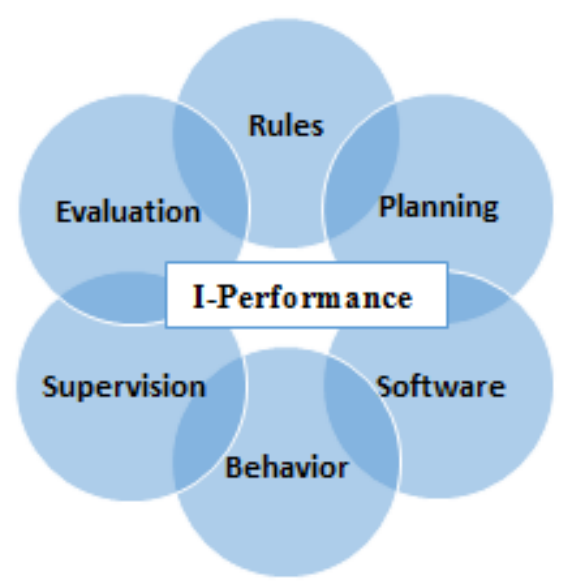

Figure 1. Stages of the research methodology

In universities in Indonesia, it is very important to make a rule that will be applied to every lecturer who will implement Tri Dharma, this is a reference for lecturers' performance in a university. I-Performance context in this case, that each lecturer has a plan according to a self-determined time span. This condition gives freedom to regulate a work program that is measured according to the ability of the lecturer concerned, which results in the formation of a behavior culture according to the conditions and performance of each lecturer. Most of the time, employees must work in interdependent teams and in uncertain work environments.

The community of software developers always provides opportunities for team members to work together and develop themselves in an interdependent unit (Ganesh, Gupta, 2010). Software in its application as a controller to connect the planned activities with monitoring implementation. Furthermore, the leaders can evaluate the performance of the work program that has been created and implemented by the lecturer itself as a form of accountability. The behavior here shows the actions of exhibition people to complete a job, meanwhile the results aspect states about the individual consequences of work behavior (Campbell, 1990). The description refers to the picture above regarding parameters related to lecturer performance.

The change referred to in this case is that lecturers do not have to wait for instructions from the leader or institution to carry out a work program that will be seen in the progress of their performance. However, they can create 
their own programs (research and service community) according to their needs and abilities to be included in the I-Performance application. This application will then record all parameters that will become the controller for lecturers who will carry out the program to completion, including reports that must be produced. Although there are a number of studies that state that changes in work culture will make life less comfortable or feel threatened (Martin, 2013), this change in work culture is aimed for nothing but so that organizations can be more competitive (Pieterse, Caniels, Homan, 2012). Besides that, competitive improvement in changing work culture needs to be adapted to current technological developments (Weippert, 2001).

In other studies, e-Performance is a business process that can increase organizational success by improving employee performance (Al-Raisi, Amin, Tahir, 2011). Success in software applications that are designed needs to provide good functionality so that transactions and access made by lecturers would not be constrained in order to make application performance can also provide various information more quickly and accurately (Sarojadevi, 2011). Embedded application software design for the needs of an increase in performance is nothing but to help and motivate lecturers to be more concerned with their performance related to research and community service to the community. At present, there are so many application developments in the field of information technology in facilitating the access, management, and interaction of lecturers for an activity such as embedded eLearning which successfully helps lecturers in directing and informing various knowledge and experiences for their students in improving the learning process (Khan and Ali, 2017; Likitrattanaporn, 2018; Miyaji, 2018; Eketu, 2018; Allam, 2018; Andriansyah et al., 2018; Manzuma-Ndaaba et al., 2018; Bagherpour \& Shamshiri, 2018; Tayebi et al., 2019).

Another approach that can be used as a reference from I-Performance, is that based on the success of previous research where e-Learning culture was able to solve problems, critical learning, and creativity for students (Zare, Sarikhani, Salari, Mansouri, 2016), meaning that the interaction role between lecturers as facilitators is able to motivate students in increasing their productivity which results in changes in the way students learn according to their own comfort. It was also concluded in other studies about cultural change learning that e-Learning is a technology that has increasingly improved service capabilities and is popular in modern society (Yanuschika, Pakhomovaa, Batbolda, 2015). Based on the reference of the research, it is certainly very appropriate to implement I-Performance embedded related to the performance of the Tri Dharma of Higher Education in universities in Indonesia which are directed to increase lecturer performance motivation.

\section{Work Culture}

Tri Dharma of Higher Education is a form of performance that represents the level of productivity of higher education institutions in Indonesia. The performance referred to in this case is the grouping of fields of performance based on teaching; research; and service. A number of universities in Indonesia that have directed the performance of lecturers in the field of teaching in addition to direct face-to-face (conventional learning methods) have also used embedded e-Learning so that the performance of lecturers in interacting using e-Learning tools can be more creative than just face-to-face meetings. Teaching performance is also a routine where the level of monitoring has been measured and is commonly performed by lecturers so that the performance of the teaching field has been very well done by all lecturers in each university.

However, it is very different from the performance of the research field which varies greatly in determining the object and its research criteria, so it requires lecturers' motivation and support from higher education institutions to facilitate research activities. This condition makes the performance of the field of research also does not have a measure of the timing of its implementation because there is no similar routine process to the performance of the teaching field. This makes lecturers become less focused in the field of research which also causes performance to be unplanned properly and does not increase research productivity (Ahmed, Umrani, Qureshi \& Sarmad, 2018; Ali \& Haseeb, 2019; Haseeb, Abidin, Hye, \& Hartani, 2018; Haseeb., 2019; Suryanto, Haseeb, \& Hartani, 2018).

Likewise, the performance of the community service sector is no better than the performance of the field of research where the level of implementation of performance is also not optimal. In the field of community service, in addition to its unmeasured implementation time, the results do not always provide scientific evaluations as well as publications in the performance of the research field. This condition also makes lecturers unmotivated to do community service because the tendency of the views of a number of lecturers is only volunteerism that wants to dedicate their knowledge in the community. Various performance conditions in the three fields discussed above led to the need for motivated lecturers and at the same time carrying out their performance optimally in the field of research and service. A mere desire without optimal effort cannot produce productivity in performance, so there needs to be a change in the work culture that can help lecturers in planning a more productive performance. The measure of increasing productivity is nothing but the amount of performance that must be done by lecturers in the field of research and community service, including the field of teaching. This has become a lecturer work culture that is common in universities in Indonesia so that various 
strategies need to be done for increasing performance that impacts on work productivity (Spathopoulou and Papakonstantinidis, 2017; Chidobi, 2017; Stavrou, 2018).

\section{Design Analysis}

Embedded I-Performance in the performance execution of Tri Dharma is needed to control the various performance plans that will be planned up to the implementation carried out by each lecturer. Control parameters that can be monitored in real time according to the level of activity carried out by the lecturer concerned which is instructed by the lecturer and the I-Performance application that will provide a reminder for each timetable set by the lecturer. The important parameters in I-Performance which are self-regulated by lecturers are as follows:

1. Planning work programs from each field, namely the field of teaching; research field; and the field of community service (Independent),

2. Lecturers who have planned an independent work program will automatically be assigned a letter of assignment from their leader in accordance with the proposed planning of the lecturer program (Delegation),

3. Supervision is a reminder for the lecturers concerned as the implementer of the program that has been proposed by themselves (Monitoring),

4. Report the results of activities according to the time determined by the lecturer for reference evaluation (Transparency),

5. Recapitulation of various performance in each field based on the final report that has been carried out (Accountability).

The parameters mentioned above are a reference to see whether there is a change in work culture and increase in productivity in the performance of lecturers by utilizing the I-Performance application. This can be followed up by the lecturer concerned by measuring the extent of his ability to plan until complete various tasks. Of course, the results of the program that was planned to be completed will be recorded directly by the lecturer concerned because the I-Performance monitoring and evaluation application will display the recapitulation of all plans in real time until the completion of a program in all three fields according to the lecturer's own making. At that time, the lecturer can see in real time the performance that has been achieved in good condition or has no improvement at all. The reminder in I-Performance will help lecturers to be motivated in performing more creative performance as the increase in student performance in e-Learning activities (Pervin and Khan 2017; Sabbah, 2017; Dincer and Kilinç, 2018).

The following is the desired strategy so that lecturers can measure the level of achievement of their own work programs and be more motivated by utilizing I-Performance. Of course, the more finished program planning which is done by the lecturer, then the performance will also increase; either done by the lecturer in a continuous or parallel program and also possible in groups or individuals. Next, regarding the system that displays the flow of lecturer activities using I-Performance and data management on I-Performance.

The implementation design of the I-Performance system is divided into 3 levels, namely: 1) The first level, is the first stage that needs to be described regarding the description of the needs and flow of data and information from the business process regarding the control over interactions between users and the I-Performance application. It can be seen that the lecturers will interact with the I-Performance application, where the relevant user data related to registration, lecturer planning activities, lecturer activity progress, and monitoring of lecturer activities is being shown. Furthermore, I-Performance will inform in real time the recorded activities related to the lecturer data in question and will provide a warning sign, especially on planned program activities and the ones close to the implementation period's deadline. 2) The second level is related to application modules that will be built according to the needs of service to the lecturers. Modules will be developed related to lecturer administrative services, lecturer planning (activities), the recapitulation of various plans, and the final report on activities. All of them will be recorded according to the data inputted by the user and reminder system will control the completion time of activities based on what has been planned by themselves. 3) The third level is going to explain about the data storage stage in the database which includes the database of user administration verification, lecturer activity database, and database reports on each user activity. In addition, this level also describes physical storage media and servers used for the management of all databases that have been designed by the application module.

The description of the performance improvement strategy referred to in the use of I-Performance applications can be seen from some of the conditions that have been done by each lecturer, namely:

1. Increased the number of lecturers' involvement in executing performance,

a. Increased number of initiatives/participation of lecturers who will plan work programs

b. Increased motivation of lecturers who carry out work program planning that will automatically get an assignment letter according to the plan from the leader,

c. Increased completion of work programs in a timely manner because the implementation period until performance report has been determined according to the ability of each lecturer,

d. Increased opportunities for lecturer work program planning made according to each plan (parallel performance). 
2. Increased the trust of lecturers in monitoring and evaluating performance with the use of I-Performance application,

a. Increased the individually or in groups activity of lecturers in managing their work programs through automatic reminder which will always remind the responsibility of implementing the program,

b. Improvement of work programs that produce outcomes with the obligation to report on various achievements because the leader can monitor the process until the final results in real time.

3. Significant reduction related to the gaps in terms of decreasing motivation (ignorance) in contributing/achievement of programs in the faculty environment is spotted,

a. Reduced the gap between active and non-active lecturers in contributing to work programs because the performance progress is always visible,

b. Increased work motivation with many programs made individually or in groups by lecturers,

c. Increased awareness of lecturers to run a work program because everyone actively measures and monitors their respective performance,

d. Increased utilization of I-Performance by lecturers because performance appraisal is only through databases that are within I-Performance.

4. Increased collaboration between permanent lecturers in sharing information independently or in groups, a. Increased percentage of permanent lecturers who utilize I-Performance either independently or in groups,

b. Increased variation and the number of working groups planning work programs that are not just individual lecturers' programs.

5. The progress of implementing the I-Performance application as a performance control for each lecturer.

a. Real-time evaluation of the performance of planning, implementation, and reporting that provides the performance conditions of the lecturer concerned,

b. Resulting recapitulation of performance from the lecturers, either individually or in groups, can be monitored directly and effectively,

c. A leader will be able to monitor all conditions of lecturer performance in real time so that preventive actions can be given through measurable reward and punishment.

\section{Research Implications}

The following is a percentage chart that shows an increase in productivity that occurs during the implementation of work programs using I-Performance application performed by each lecturer. The assessment performance parameters include increasing work productivity; program planning; progress of program completion (early-on-time-late); final document evaluation (complete documents-lack of complete documents).

Table 1. Lectures Performance Productivity

\begin{tabular}{|c|c|c|c|c|c|c|c|c|c|}
\hline & \multicolumn{3}{|c|}{ Teaching } & \multicolumn{3}{|c|}{ Research } & \multicolumn{3}{|c|}{ Community Service } \\
\hline & Early & $\begin{array}{l}\text { On } \\
\text { Time }\end{array}$ & Replacement & Early & $\begin{array}{l}\text { On } \\
\text { Time }\end{array}$ & $\begin{array}{l}\text { Late } \\
\text { Time }\end{array}$ & Early & $\begin{array}{l}\text { On } \\
\text { Time }\end{array}$ & $\begin{array}{l}\text { Late } \\
\text { Time }\end{array}$ \\
\hline \multicolumn{10}{|l|}{ Program Planning ( $\sum$ lecturers $)$} \\
\hline Individual Involvement & & $100 \%$ & & & $80 \%$ & & & $50 \%$ & \\
\hline Group Involvement & & $15 \%$ & & & $10 \%$ & & & $85 \%$ & \\
\hline \multicolumn{10}{|l|}{$\begin{array}{c}\text { Implementation of Planning } \\
\text { Programs }\end{array}$} \\
\hline Individual Involvement & & $81 \%$ & $9 \%$ & $2 \%$ & $95 \%$ & $3 \%$ & & $98 \%$ & $4 \%$ \\
\hline Group Involvement & & $80 \%$ & $10 \%$ & $2 \%$ & $80 \%$ & & $5 \%$ & $95 \%$ & \\
\hline \multicolumn{10}{|l|}{ Corrective Action } \\
\hline Individual Involvement & $2 \%$ & $98 \%$ & & $2 \%$ & $97 \%$ & $1 \%$ & $2 \%$ & $98 \%$ & \\
\hline Group Involvement & $1 \%$ & $99 \%$ & & $2 \%$ & $98 \%$ & & $1 \%$ & $99 \%$ & \\
\hline \multicolumn{10}{|c|}{ The Completeness of Document } \\
\hline Individual Involvement & $100 \%$ & & & & $98 \%$ & $2 \%$ & $1 \%$ & $99 \%$ & \\
\hline Group Involvement & $100 \%$ & & & & $100 \%$ & & & $100 \%$ & \\
\hline
\end{tabular}


The results of having I-Performance embedded into a university system is a significant increase in performance in the field of research and service. Initially, lecturer performance averaged around $27 \%$ from the research field and $15 \%$ from the community service field, while after applying I-Performance the results increased to $75 \%$ for the research field and $50 \%$ for the community service field. As in table 1 which presents data on the performance of lecturers conducted in four groups; namely proposing work programs, implementing the proposed program, controlling the program, and completing the documents produced. The performance is mapped based on the fields of teaching, research, and community service that not only lecturers do perform their performance individually, but among these lecturers also perform in the form of groups.

\section{Conclusions}

I-Performance is an application that is embedded in universities and aims to change the work culture of the lecturer so that it can encourage the creation of performance according to the various ability of each lecturer. The impact of the use of I-Performance gives a reminder for lecturers to always be reminded of the responsibility of their proposed program, which must be done because their performance information is always presented in the I-Performance application in real time. This performance report is in accordance with the reporting actions into the I-Performance application at any time, which was previously carried out by the lecturers themselves according to the initial planning proposal that was recorded in the database. Performance in each implementation program carried out by lecturers is recapitulated in I-Performance in real time and monitored not only by the lecturer concerned but the leader can also assess the performance of the lecturers concerned.

\section{REFERENCES}

[1] Abdulaziz Al-Raisi, Saad Amin, and Saad Tahir, "Evaluation of e-performance analysis and assessment in the United Arab Emirates (UAE) Organizations", Journal of internet and information system, Vol. 2(2), July 2011, pp. $20-27$.

[2] Achim Weippert (QUT), "Industry Culture: A Need for Change", Report 2001-008-C-05, The Australian Cooperative Research Centre for Construction Innovation.

[3] Campbell, J.P. "Modeling the performance prediction problem in industrial and organizational psychology", Handbook of industrial and organizational psychology, Palo Alto, CA: Consulting Psychologists Press, 1990, pp. 687-732.

[4] Chidobi, R. U. (2017). Extent of Implementation of Nuc
Regulation by Private Universities in Enugu State on Personnel Management. American Journal of Education and Learning, 2(1), 83-91.

[5] Dincer, N., \& Kilinç, Z. (2018). The Analysis of Stress Levels of the Female Wrestlers Studying in Higher Education (A Case of Batman Province). Asian Journal of Education and Training, 4(3), 156-160.

[6] Eketu, C. A. (2018). Perspectives on Human Nature and Implications for Research in the Behavioural Sciences. International Journal of Emerging Trends in Social Sciences, 4(1), 42-46.

[7] Ganesh, M. P., \& Gupta, M., "Impact of virtualness and task interdependence on extra-role performance in software development teams", Team Performance Management, 2010, pp. 169-186.

[8] H. Sarojadevi, "Performance Testing: Methodologies and Tools", Journal of Information Engineering and Applications, Vol- 1, No.5, 2011.

[9] Istambul M. Rozahi, "E-Learning Design Activity to Improve Student's Knowledge and Skills: A Case Study of Database Design Courses", International Journal of Information and Education Technology, Vol. 6, No. 6, June 2016, pp. 423-429.

[10] Jason Martin, "Organizational Culture and Organizational Change: How Shared Values, Rituals, and Sagas can Facilitate Change in an Academic Library", ACRL 2013, April 10-13, Indianapolis, 2013.

[11] Jos H. Pieterse, Marjolein C.J. Caniëls, Thijs Homan, "Professional discourses and resistance to change", Journal of Organizational Change Management Emerald Article: Professional discourses and resistance to change, Journal of Organizational Change Management, Vol. 25 No. 6, 2012, pp. 798-818.

[12] Khan, S. N., \& Ali, E. I. E. (2017). The moderating role of intellectual capital between enterprise risk management and firm performance: A conceptual review. American Journal of Social Sciences and Humanities, 2(1), 9-15.

[13] Likitrattanaporn, W. (2018). A Study of Language Learning Strategies for Practical Use through the Process of Cooperative Learning. International Journal of Educational Technology and Learning, 3(1), 35-44.

[14] Miyaji, I. (2018). Comparison of Useful Activities of Improving Awareness in Blended Classes in Java Script and PHP Programming. International Journal of Educational Technology and Learning, 3(2), 78-92.

[15] Olga V. Yanuschika, Elena G. Pakhomovaa, Khongorzul Batbolda, "E-learning as a Way to Improve the Quality of Educational for International Students", International Conference for International Education and Cross-cultural Communication. Problems and Solutions (IECC-2015), 09-11 June 2015, pp. 147 - 155.

[16] Pervin, N., \& Khan, M. N. (2017). Sexism in Language: A Legacy of Male Thought Process. International Journal of English Language and Literature Studies, 6(4), 78-90.

[17] Sabbah, S. S. (2017). The Role of Leadership in the Development of the Creative School in Palestine. Journal of Education and e-Learning Research, 4(1), 1-7. 
[18] Spathopoulou, F., \& Papakonstantinidis, S. (2017). Culture as a parameter in assessing students performance. Humanities and Social Sciences Letters, 5(3), 72-78.

[19] Stavrou, P. D. (2018). Psychoanalytic Psychotherapy as a Treatment for Depression in Adolescents: A Case Study. Global Journal of Social Sciences Studies, 4(2), 91-101.

[20] Zare, Sarikhani, Salari, \& Mansouri, "The Impact of E-Learning on University Students Academic Achievement and Creativity", Journal of Technical Education and Training (JTET), Vol. 8, No.1, June 2016

[21] Allam, Z. (2018). Students' perception of quality in higher education: An empirical investigation. Management Science Letters, 8(5), 437-444.

[22] Andriansyah, A., Taufiqurokhman, T., \& Wekke, I. (2019). Responsiveness of public policy and its impact on education management: An empirical assessment from Indonesia. Management Science Letters, 9(3), 413-424.

[23] Manzuma-Ndaaba, N., Harada, Y., Nordin, N., Abdullateef, A., \& Rahim, A. (2018). Application of social exchange theory on relationship marketing dynamism from higher education service destination loyalty perspective. Management Science Letters, 8(10), 1077-1096.

[24] Bagherpour, M., \& Shamshiri, B. (2018). The effect of educational methods on creativity of pre-school children: A case study. Management Science Letters, 8(6), 717-724.

[25] Tayebi, S., Manesh, S., Khalili, M \& Sadi-Nezhad, S. (2019). The role of information systems in communication through social media.International Journal of Data and Network Science, 3(3), 245-268.

[26] Ahmed, U., Umrani, W. A., Qureshi, M. A., \& Samad, A. (2018). Examining the links between teachers support, academic efficacy, academic resilience, and student engagement in Bahrain. INTERNATIONAL JOURNAL OF ADVANCED AND APPLIED SCIENCES, 5(9), 39-46.

[27] Ali, A., \& Haseeb, M. (2019). Radio frequency identification (RFID) technology as a strategic tool towards higher performance of supply chain operations in textile and apparel industry of Malaysia. Uncertain Supply Chain Management, 7(2), 215-226.

[28] Haseeb, M., Abidin, I. S. Z., Hye, Q. M. A., \& Hartani, N. H. (2018). The Impact of Renewable Energy on Economic Well-Being of Malaysia: Fresh Evidence from Auto Regressive Distributed Lag Bound Testing Approach. International Journal of Energy Economics and Policy, 9(1), 269-275.

[29] Suryanto, T., Haseeb, M., \& Hartani, N. H. (2018). The Correlates of Developing Green Supply Chain Management Practices: Firms Level Analysis in Malaysia. International Journal of Supply Chain Management, 7(5), 316. 